\title{
Informative advertising in differentiated oligopoly markets ${ }^{\text {t⿱ }}$
}

\author{
Stephen F. Hamilton \\ Department of Economics, California Polytechnic State University, San Luis Obispo, CA 93407, United States
}

\begin{abstract}
A B S T R A C T
This paper examines the welfare implications of informative advertising in differentiated product oligopoly markets. The analysis reconciles the conflicting results in previous studies that find advertising to be undersupplied in homogeneous product markets, but oversupplied in differentiated product markets when the degree of differentiation is "small". In equilibrium, purely informative advertising is undersupplied when brands are sufficiently close substitutes and oversupplied when brands are more differentiated. Product differentiation also has welfare implications for the effect of technological change in the advertising sector. In response to an advertising cost innovation, equilibrium prices fall and the market converges to the socially optimal resource allocation for brands that are sufficiently close substitutes, whereas equilibrium prices rise and divergence occurs when brands are more differentiated.
\end{abstract}

\section{Introduction}

An important role of advertising is to provide consumers with factual information about product attributes. Advertising that informs consumers about product specifications benefits society both by stimulating the exchange of products to new customers and by facilitating better matches between existing customers and brands. But advertising is also a costly activity, for instance annual advertising expenditures in the U.S. represent approximately $2.3 \%$ of GDP (Advertising Age), and delivering informative advertisements to consumers who are already informed about products is a socially wasteful activity.

This paper addresses the efficiency of informative advertising outcomes in oligopoly markets. Social and private advertising incentives differ in the model due to three external effects, the relative importance of which depends on how the value of information is capitalized among "new" and "existing" customers in the market. Informative advertising that reaches new consumers embodies an externality familiar to search goods: The cost of search is borne entirely by the searcher, while the benefits are divided between the searcher and the agent with whom she trades. This market size effect causes advertising to be undersupplied in the market equilibrium. Informative advertising that reaches existing consumers of a rival brand potentially improves the matches between consumers and brands, thereby raising consumer utility. Because advertising firms are

\footnotetext{
is I thank Glenn Harrison, Robert Innes, Jeff Perloff, Tim Richards, and Kyle Stiegert for helpful comments. Financial support from the Food System Research Group at the University of Wisconsin is gratefully acknowledged.
}

unable to fully appropriate these rents, this matching effect also causes advertising to be undersupplied in the market equilibrium. But informative advertising by one brand that reaches existing consumers of a rival brand also serves to attract customers away from rivals, an activity that is less valuable to society than to individual firms. This business-stealing effect causes advertising to be oversupplied in the market equilibrium.

The analysis is framed by a differentiated-product oligopoly model with imperfect information. Consumers have heterogeneous tastes for product attributes, but are unaware of the attributes contained in individual brands without receiving an advertisement from that brand. The role of advertising is to convey factual information to consumers about the prices and product specifications of the advertised brand. Grossman and Shapiro (1984) (henceforth GS) employ this framework to compare private and social advertising outcomes in a model with highly substitutable brands. GS demonstrate that advertising decreases equilibrium prices and that the market level of advertising exceeds the socially optimal level of advertising when the brands are sufficiently close substitutes. Soberman (2004) extends this model to show that the equilibrium price is increasing in the level of advertising for more differentiated brands, but does not examine welfare implications as done here.

The basic message of this paper is that the efficiency of markets for purely informative advertising depends on the extent of product differentiation in the industry. The reason is that the market size effect and the matching effect decrease with the degree of product differentiation in the market, while the business-stealing effect increases (up to the limit of oligopoly interaction in the market). For highly substitutable products, informative advertising produces relatively large market size effects and negligible business-stealing effects. Advertising, accordingly, is undersupplied. For more 
differentiated goods, the business-stealing effect dominates the combined influence of the market size and matching effects, and advertising is oversupplied. However, for still more differentiated products, local monopoly markets emerge: The business-stealing externality vanishes, and advertising is again undersupplied.

The analysis reconciles some conflicting results in the advertising literature. In particular, the welfare implications of informative advertising under differentiated, but highly substitutable brands in GS contrasts with the welfare implications that emerge in models with homogenous goods. Stegeman (1991) and Stahl (1994) show that purely informative advertising exists only in mixed strategies and is always undersupplied under price competition, and Gary-Bobo and Michel (1991) find that advertising does not occur at all as the number of firms becomes large under quantity competition. ${ }^{1}$ This distinction turns out to arise from the use of the "large group" assumption of Dixit and Stiglitz (1977) in differentiated product models. The present paper removes this assumption and demonstrates that advertising is always undersupplied (in pure strategies) below a critical level of product differentiation.

The paper also numerically examines the welfare implications of technological change in the advertising sector. Technological change is important in advertising markets, as the emergence of new media, for instance digital platforms and content networking on the internet, can reduce the cost of achieving a given reach of an ad campaign. In response to an advertising cost innovation, advertising frequencies rise, and this produces welfare implications that depend on the extent of product differentiation in the market. For highly substitutable products, greater advertising frequencies increase demand elasticities (and reduce prices), and the market equilibrium converges to the social optimum. For highly differentiated products, greater advertising frequencies decrease demand elasticities and raise equilibrium prices. A reduction in advertising cost exacerbates both advertising and price distortions in the market, and the market equilibrium diverges from the social optimum.

The remainder of the paper is structured as follows. The next section describes consumer demand for differentiated products. Section 3 derives market equilibria under local monopoly and two types of oligopoly that emerge according to whether or not advertisements received by consumers who are already aware of the rival brand create new consumption units. Section 4 calculates the socially optimal advertising allocation and presents a comparison of optimal and market advertising levels, with numerical analysis provided to support the main results.

\section{Informative advertising and consumer demand}

Consider a duopolistic industry in which firms sell differentiated brands to consumers. Each consumer is atomistic and has unit demand. Consumers rely on information received from advertisements to locate specific brands in the product space and do not engage in any activities to acquire information other than by viewing ads. The advertisements are truthful and convey information about the existence of products and the attributes contained in each brand.

Brands in the model differ according to their characteristics in the sense of Lancaster (1975). The role of advertising is to match consumers to the products that best suit their tastes. This demand structure is represented by a Hotelling (1929) "linear city", in which consumers are identified according to points on a line segment that correspond to their ideal product characteristics. ${ }^{2}$ Firms are located at

\footnotetext{
${ }^{1}$ In Gary-Bobo and Michel (1991), advertising is a collective good that shifts the demand of all firms. Their results are in accordance with the general outcome of oligopoly models when firms invest in a collective good.

${ }^{2}$ The merit of this approach over a Salop (1979) circular city model is its simplicity, and the two models produce qualitatively similar results in settings without entry.
}

the endpoints of the line segment and consumers are distributed uniformly with unit density over the interval.

Each consumer purchases at most one unit and receives a gross value of $v$ from consuming the product. Consumers incur transportation costs of $t$ per unit of distance, so that the net surplus enjoyed by a consumer who purchases a brand a distance $x$ units away at a price of $p$ is $v-p-t x$. Consumers purchase the product only if they are aware of a brand in the product category that offers positive net surplus, and a consumer who is aware of both brands selects the brand that provides the highest net surplus.

Following Butters (1977), the advertising process is specified by assuming firms send independent advertising messages and have no ability to target advertisements towards consumers located at particular points in the product space. ${ }^{3}$ Let $\phi_{i}$ denote the advertising intensity of firm $i$. Advertising intensity is measured in terms of the reach of the ad campaign, so that $\phi_{i}$ is interpreted as the fraction of the consumer population that is exposed, at least once, to the advertising message of firm $i$. This divides consumers at each location in the product space into four types: With probability $\phi_{i} \phi_{j}, j \neq i$, a consumer simultaneously receives advertising messages from both brands; with probability $\phi_{i}\left(1-\phi_{j}\right)$ a consumer receives an ad from brand $i$ but not from brand $j$; with probability $\left(1-\phi_{i}\right) \phi_{j}$ a consumer receives an ad from brand $j$ but not from brand $i$; and with probability $\left(1-\phi_{i}\right)\left(1-\phi_{j}\right)$ a consumer fails to receive any advertising message at all. Aggregate demand facing each firm sums the demand functions among consumers of each type.

The market equilibrium studied is the symmetric, non-cooperative Nash equilibrium in prices $(p)$ and advertising intensities $(\phi)$. There are four types of market equilibrium. First, there are mixed strategy equilibria: For various levels of product differentiation these are the only equilibria that exist. Apart from the regions that contain only mixed strategy equilibria, a monopoly region and two oligopoly regions emerge that support symmetric, pure strategy Nash equilibria. If the market prices are set at a level that a fullyinformed consumer located at the midpoint of the segment buys neither brand (i.e., demand regions do not "overlap"), a local monopoly equilibrium emerges. If all fully-informed consumers make a purchase at the prevailing market prices, the type of oligopoly equilibrium that emerges depends on whether prices are set at a level that also induces all partially informed consumers to purchase the brand. Partially-informed consumers travel farther (on average) than fully-informed consumers in the market, because imperfect information can lead to inferior matches between consumers and brands. The market is described hereafter to be "completely covered" if all consumers who receive at least one advertising message purchase a brand at prevailing prices, $t \leq(v-p)$; and the market is described to be "incompletely covered" if at least one partially informed consumer does not make a purchase at prevailing prices: $t / 2 \leq(v-p)<t$.

GS consider the case of complete coverage. The equilibrium prices in their model are assumed to be sufficiently low that all consumers receiving an advertising message purchase the product, even if doing so requires traveling the entire length of the line segment. Under incomplete coverage, the equilibrium prices are low enough that a fully informed consumer located at the midpoint of the line segment purchases the product, $v-p \geq t / 2$, but high enough that a partially informed consumer located at the endpoint of the line finds it prohibitively costly to travel the entire length of the line segment to purchase the more distant brand, $v-p<t$.

Among the fully informed population of consumers, let $x_{f}^{i}\left(p_{i}, p_{j}\right)$ denote the distance from firm $i$ to the consumer who is indifferent

\footnotetext{
${ }^{3}$ For an analysis of the case of targeted advertising, see Iyer, Soberman, and Villas-
} Boas (2005). 
between purchasing brand $i$ and brand $j(j \neq i)$ at prices $p_{i}$ and $p_{j}$. The location of $x_{f}^{i}\left(p_{i}, p_{j}\right)$ is given algebraically by

$x_{f}^{i}\left(p_{i}, p_{j}\right)=\left(t+p_{j}-p_{i}\right) / 2 t$.

All fully informed consumers at locations $x \leq x_{f}^{i}\left(p_{i}, p_{j}\right)$ prefer brand $i$ to brand $j$, so that Eq. (1) defines the demand facing brand $i$ from its fully informed consumers. Firms also face demand from partially informed consumers. Let $x_{p}^{i}\left(p_{i}\right)$ denote the location of the partially informed consumer who is indifferent between purchasing brand $i$ at a price of $p_{i}$ or purchasing nothing at all. ${ }^{4}$ This value is given by

$x_{p}^{i}\left(p_{i}\right)=\left(v-p_{i}\right) / t$

Consumers located between $x_{f}^{i}\left(p_{i}, p_{j}\right)$ and $x_{p}^{i}\left(p_{i}\right)$ would prefer brand $j$ to brand $i$ if fully informed, but nevertheless prefer brand $i$ to consuming nothing at all when partially informed.

Demand for each firm is described below for each of the three regions that define the degree of market coverage. For ease in exposition, the degree of market coverage is expressed for now in terms of the (endogenous) prices. The relationship between the model primitives and the type of market coverage is considered in the subsequent section.

Under local monopoly, $2(v-p)<t$, a consumer located at the midpoint of the line does not purchase either brand, even when fully informed. Hence, demand facing the representative firm depends only on the population of consumers that receive his advertising message. Demand for product $i$ accordingly is

$\hat{X}^{i}\left(\hat{p}_{i}, \hat{\phi}_{i}\right)=\hat{\phi}_{i} x_{p}^{i}\left(\hat{p}_{i}\right)=\hat{\phi}_{i}\left(v-\hat{p}_{i}\right) / t, \quad i=0,1$

Notice that the price elasticity of demand under local monopoly, $\hat{\varepsilon}=\hat{p} /(v-\hat{p})$, is not a function of the advertising level. Advertising messages are as likely to strike nearby consumers as ones farther away, and it follows that advertising produces purely a scaling effect on demand.

Under incomplete coverage, $(v-p)<t \leq 2(v-p)$, all fully informed consumers purchase one of the two brands, but a partially informed consumers located on the far end of the line segment from the advertised brand does not make a purchase. The demand for brand $i$ is given by the weighted sum of the demands in Eqs. (1) and (2),

$X^{i}\left(p_{i}, p_{j}, \phi_{i}, \phi_{j}\right)=\phi_{i} \phi_{j} x_{f}^{i}\left(p_{i}, p_{j}\right)+\phi_{i}\left(1-\phi_{j}\right) x_{p}^{i}\left(p_{i}\right) \quad i \neq j, i=0,1$,

Simplifying this expression using Eqs. (1) and (2) gives

$X^{i}\left(p_{i}, p_{j}, \phi_{i}, \phi_{j}\right)=\frac{\phi_{i}}{2 t}\left(2\left(1-\phi_{j}\right) v+\phi_{j} t-\left(2-\phi_{j}\right) p_{i}+\phi_{j} p_{j}\right), \quad i \neq j, i=0,1$.

In the symmetric case, the price elasticity of demand facing firm $i$, $\varepsilon_{i}=-\left(\partial X^{i} / \partial p_{i}\right) p_{i} / x_{i}$, evaluated at $p_{i}=p, X^{i}=X$, and $\phi_{i}=\phi$ for $i=0,1$, is given by $\varepsilon=\frac{(2-\phi) p}{2(v-p)(1-\phi)+\phi t^{t}}$. is straightforward to verify that advertising makes demand less elastic (and therefore raises prices) under incomplete coverage. The reason is that demand in Eq. (4) is a weighted average of the demand of fully informed and partially informed consumers, with weights given by the equilibrium advertising frequencies. The elasticity of demand of fully informed consumers in Eq. (1) is $\varepsilon_{f}=p / t$, and the elasticity of demand of partially informed consumers in Eq. (2) is $\varepsilon_{p}=p /(v-p)$. Because $v-p<t$ must hold in equilibrium under incomplete coverage, it follows that $\varepsilon_{f}<\varepsilon_{p}$. An increase in the equilibrium

\footnotetext{
${ }^{4}$ By the definition of incomplete coverage, this consumer resides on the unit interval.
}

advertising intensity expands the share of fully informed consumers in the market, and this decreases the price elasticity of demand.

Under complete coverage $(t \leq v-p)$, the demand for brand $i$ is given by

$\tilde{X}^{i}\left(\tilde{p}_{i}, \tilde{p}_{j}, \tilde{\phi}_{i}, \tilde{\phi}_{j}\right)=\tilde{\phi}_{i} \tilde{\phi}_{j} x_{f}^{i}\left(\tilde{p}_{i}, \tilde{p}_{j}\right)+\tilde{\phi}_{i}\left(1-\tilde{\phi}_{j}\right) x_{p}^{i}\left(\tilde{p}_{i}\right), \quad i \neq j, i=0,1$,

Noting (by definition) that all partially informed consumers of brand $i$ make a purchase under complete coverage, $x_{p}^{i}\left(\hat{p}_{i}\right)=1$, the demand for brand $i$ is

$\tilde{X}^{i}\left(\tilde{p}_{i}, \tilde{p}_{j}, \tilde{\phi}_{i}, \tilde{\phi}_{j}\right)=\tilde{\phi}_{i}\left(\tilde{\phi}_{j}\left(\frac{t+\tilde{p}_{j}-\tilde{p}_{i}}{2 t}\right)+1-\tilde{\phi}_{j}\right)$

The price elasticity of demand, $\tilde{\varepsilon}_{i}$, evaluated at the symmetric Nash equilibrium point $\left(\tilde{p}_{i}=\tilde{p}, \tilde{X}^{i}=\tilde{X}\right.$, and $\tilde{\phi}_{i}=\tilde{\phi}$ for $\left.i=0,1\right)$ is given by $\tilde{\varepsilon}=\hat{p} \hat{\phi} / t(2-\hat{\phi})$. As in GS, an increase in the level of informative advertising increases demand elasticities (and reduces prices). The reason is that demand is perfectly inelastic (up to the reservation level) for the subgroup of partially informed consumers under complete coverage. Advertising, which increases the share of fully informed consumers in the market, therefore makes demand more price elastic.

\section{Market allocation}

Suppose each firm produces a single brand at marginal production cost of $c>0.5$ The cost of sending an advertising message through the unit population density is $A(\phi ; \alpha)$, where $\alpha$ is a shift parameter that reflects the available advertising technology. Among other things, a reduction in $\alpha$ captures the effect of the emergence of new media such as digital platforms that can reduce the cost of achieving a given reach in an ad campaign. The advertising cost function has the following properties: $A_{\phi}>0, A_{\alpha}>0, A_{\phi \phi}>0$ and $A_{\phi \alpha}>0$.

The market advertising allocation can be classified according to the degree of product differentiation $(t)$, net consumption benefits $(v-c)$, and the advertising cost level $(\alpha)$. For a range of parameter values: (i) a local monopoly equilibrium exists; (ii) a symmetric, pure strategy Nash equilibrium exists in the complete coverage region; and (iii) a symmetric, pure strategy Nash equilibrium exists in the incomplete coverage region. ${ }^{6}$ For alternative parameterizations of the model, however, equilibrium exists only in mixed strategies. For instance, when advertising costs are low and the products are highly differentiated, a firm's best response to a rival that selects a price in the incomplete coverage region is to defect to the reservation price for partially informed consumers (and advertise more frequently).

For a given level of consumption benefits $(v)$, production costs $(c)$, and advertising costs $(\alpha)$, the equilibrium regions of the model can be characterized by varying the degree of product differentiation $(t)$ in the market. Specifically, let $\lambda(v, c, \alpha)$ and $\mu(v, c, \alpha)$ denote the boundaries of these regions (characterized formally below) as related to $t$. The regions of market coverage can be described as follows: (i) for $v-c<t$, a local monopoly equilibrium emerges; (ii) for $\mu(v, c, \alpha)<t \leq v-c$, a mixed strategy equilibrium occurs; (iii) for $(v-c) / 2<t \leq \mu(v, c, \alpha)$, a pure strategy equilibrium emerges with incomplete coverage; (iv) for $\lambda(v, c$, $t)<t \leq(v-c) / 2$, a mixed strategy equilibrium occurs; and $(v)$ for $t \leq \lambda(v, c$, $\alpha)$, a pure strategy equilibrium emerges with complete coverage. These regions are considered, in turn, below.

\footnotetext{
${ }^{5}$ Fixed costs, which play no role in the model, are suppressed.

${ }^{6}$ In each region, the second-order conditions hold in the neighborhood of the symmetric equilibria when $A_{\phi \phi}$ is sufficiently large. This is assumed to be the case Advertising functions that satisfy this condition include the case of $A()=.-\alpha \ln (1-f)$ considered by Butters (1977) and the case of $A()=.\alpha f^{2}$ considered by Soberman (2004)
} 


\subsection{Local monopoly: $v-c \leq t$}

The objective of firm $i$ under local monopoly is to

$$
\max _{\hat{p}_{i}, \hat{\phi}_{i}}\left(\hat{p}_{i}-c\right) \hat{X}^{i}\left(\hat{p}_{i}, \hat{\phi}_{i}\right)-A\left(\hat{\phi}_{i} ; \alpha\right)
$$

where demand is given by Eq. (3). The first order conditions for a profit maximum (evaluated in the symmetric case $\hat{p}=\hat{p}_{i}=\hat{p}_{j}$ and $\left.\hat{\phi}=\hat{\phi}_{0}=\hat{\phi}_{1}\right)$ are

$\hat{\phi}(v-2 \hat{p}+c) / t=0$

$(\hat{p}-c)(v-\hat{p}) / t=A_{\phi}(\hat{\phi} ; \alpha)$

The simultaneous solution to Eqs. (6) and (7) is $\hat{p}^{e}=(v+c) / 2$ and

$(v-c)^{2} / 4 t=A_{\phi}\left(\hat{\phi}^{e} ; \alpha\right)$.

Notice that the optimal price is not a function of the advertising level. This is because, with local monopoly markets, advertising has no effect on the price elasticity of demand. Making use of the implicit function theorem on Eq. (8), equilibrium advertising levels increase with innovations in advertising technology (i.e., smaller $\alpha$ ) and decrease with the degree of product differentiation $(t)$.

\subsection{Incomplete coverage: $(v-c) / 2<t \leq \mu(v, c, \alpha)$}

Under incomplete coverage, the objective of firm $i$ is to

$\max _{p_{i}, \phi_{i}}\left(p_{i}-c\right) X^{i}\left(p_{i}, p_{j}, \phi_{i}, \phi_{j}\right)-A\left(\phi_{i} ; \alpha\right)$,

where demand is given by Eq. (4). The first order conditions for a profit maximum, evaluated at the symmetric allocation $\left(\hat{p}=\hat{p}_{i}=\hat{p}_{j}\right.$ and $\left.\hat{\phi}=\hat{\phi}_{0}=\hat{\phi}_{1}\right)$, are ${ }^{7}$

$2(v-p)(1-\phi)+\phi t=(p-c)(2-\phi)$,

$(p-c)\left(\frac{\phi}{2}+(1-\phi) \frac{(v-p)}{t}\right)=A_{\phi}(\phi ; \alpha)$.

The optimal advertising level in Eq. (10) has the following interpretation. A small increase in advertising that informs a marginal consumer fully informs the consumer with probability $\phi$, in which case the firm acquires a purchase exactly half the time. With probability $1-\phi$, the advertising unit partially informs the marginal consumer, in which case the likelihood that the firm acquires a purchase is $(v-p) / t$, the length of the segment served by the brand. A small increase in $\phi$ therefore generates $\phi / 2+(1-\phi)(v-p) / t$ in sales and raises profits by $(p-c)(\phi / 2+(1-\phi)(v-p) / t)$. Eq. (10) states that this marginal gain be equal to the marginal cost of informing a consumer, $A_{\phi}\left(\phi_{b} ; \alpha\right)$.

To derive the boundaries for the incomplete coverage region, rearrange Eq. (9) to get

$p(\phi)=c+\frac{2(1-\phi)(v-c)+\phi t}{4-3 \phi}$.

By the definition of incomplete coverage, the price is set above the net surplus level of the most distant consumer on the segment, $v-p<t$.
Substituting $p(\phi)$ from Eq. (11) into this inequality and factoring terms yields $(v-c) / 2<t$. The price in the incomplete coverage region must also induce the consumer at the midpoint of the segment to make a purchase, $t / 2 \leq v-p$. Making use Eq. (11), this implies

$t \leq \frac{2(2-\phi)(v-c)}{4-\phi}$.

Substitution of Eq. (11) into Eq. (10) implicitly defines the equilibrium advertising level, $\phi^{e}$; that is,

$\frac{(2-\phi)[2(1-\phi)(v-c)+\phi t]^{2}}{2(4-3 \phi)^{2} t}=A_{\phi}(\phi ; \alpha) \Rightarrow \phi^{e}(v, c, t, \alpha)$.

The maximum price in the incomplete coverage region satisfies Eq. (12) with equality. Substituting $\phi^{e}(v, c, t, \alpha)$ into this equation and solving for $t$ yields the boundary value, $t^{b}=\mu(v, c, \alpha)$.

Let $p^{e}$ and $\phi^{e}$ denote the equilibrium price and advertising level that solve Eqs. (9) and (10). Making use of the implicit function theorem on these equations, it is straightforward to verify that both equilibrium advertising levels and equilibrium prices increase in response to innovations in advertising technology (i.e., smaller $\alpha$ ). ${ }^{8}$

Schmalensee (1986) reports the stylized fact that advertising intensities are positively related to industry-average profitability. This is the case here as well: Following a change in industry-specific exogenous variables $(v, c$, or $t)$, conditions that lead to greater advertising frequencies are also associated with higher industry profitability. To see this, note that demand in Eq. (4) is linear in advertising, so that profit for the representative firm can be written

$\pi(\phi ; \alpha)=A_{\phi}(\phi ; \alpha) \phi-A(\phi ; \alpha)$

Profits are increasing in advertising levels by the convexity of the advertising cost function.

\subsection{Complete coverage: $t \leq \lambda(v, c, \alpha)$}

Under complete coverage, the objective of firm $i$ is to

$\max _{\tilde{p}_{i}, \tilde{\phi}_{i}}\left(\tilde{p}_{i}-c\right) \tilde{X}^{i}\left(\tilde{p}_{i}, \tilde{p}_{j}, \tilde{\phi}_{i}, \tilde{\phi}_{j}\right)-A\left(\tilde{\phi}_{i} ; \alpha\right)$

where demand is given by Eq. (3). The first order conditions for a profit maximum, evaluated at a symmetric allocation, are

$t(2-\tilde{\phi})-\tilde{\phi}(\tilde{p}-c)=0$

$(\tilde{p}-c)(1-\tilde{\phi} / 2)=A_{\phi}(\tilde{\phi} ; \alpha)$.

The market advertising condition (14) is intuitive. A marginal increase in $\tilde{\phi}$ informs (on average) one more consumer. With probability $\tilde{\phi}$, this consumer was previously informed of the rival brand and now becomes fully informed, in which case the firm acquires a purchase exactly half the time. With probability $1-\tilde{\phi}$, this consumer becomes partially informed, in which the firm always acquires a purchase. A small increase in $\tilde{\phi}$ therefore generates $1-\tilde{\phi} / 2$ in sales to the advertising firm and raises profits by $(\tilde{p}-c)(1-\tilde{\phi} / 2)$. Eq. (14) balances this marginal gain against the marginal cost of informing the consumer, $A_{\phi}(\tilde{\phi} ; \alpha)$.

\footnotetext{
${ }^{7}$ It is possible to rule out "large deviations" in price and advertising levels from the symmetric Nash equilibrium, for instance the possibility that a firm responds to a rival that sets a price in the incomplete coverage region by setting a local monopoly price (alternatively, a complete coverage price). Details on this issue are available on request.
}

\footnotetext{
${ }^{8}$ Equilibrium advertising levels can rise or fall with an increase in the degree of product differentiation $(t)$. Advertising levels rise with $t$ when advertising costs are sufficiently low, but fall with $t$ when ads are more costly.
} 


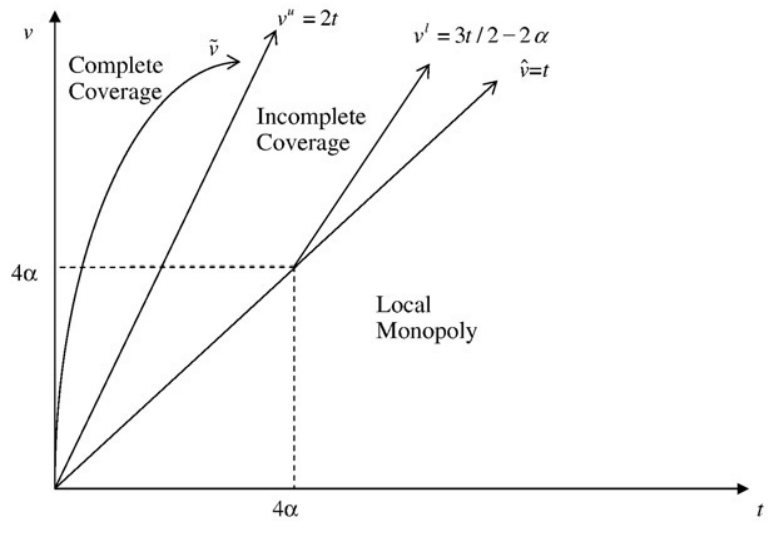

Fig. 1. Regions of market coverage under oligopoly with informative advertising $(c=0)$.

Rearranging Eq. (13), the market price satisfies

$\tilde{p}(\tilde{\phi})=c+\frac{(2-\tilde{\phi}) t}{\tilde{\phi}}$

Substituting this value into Eq. (14) defines the equilibrium advertising level, $\tilde{\phi}^{e}$,

$\frac{(2-\tilde{\phi})^{2} t}{2 \tilde{\phi}}=A_{\phi}(\tilde{\phi} ; \alpha) \Rightarrow \tilde{\phi}^{e}(t, \alpha)$.

By the definition of complete coverage, the price is set below the net surplus level of the most distant consumer on the segment, $p \leq v-t$. Substituting $\tilde{p}(\tilde{\phi})$ from Eq. (15) into this inequality and factoring terms gives $t \leq \frac{\tilde{\phi}(v-c)}{2}$. The maximum value of $t$ that leads to a symmetric pure strategy Nash equilibrium in the complete coverage region satisfies this relationship with equality; substitution of $\tilde{\phi}^{e}(t, \alpha)$ into this equation and solving for $t$ yields the boundary value $\tilde{t}^{b}=\lambda(v, c, \alpha)$.

Let $\tilde{p}^{e}$ and $\tilde{\phi}^{e}$ denote the equilibrium price and advertising level that solve Eqs. (13) and (14). Use of the implicit function theorem on these equations reveals that both equilibrium prices and equilibrium advertising levels rise with the degree of product differentiation $(t)$, whereas innovations in advertising technology (i.e., smaller $\alpha$ ) stimulate greater advertising levels and lead to lower prices.

\subsection{Boundaries between regions}

For the range of product differentiation $\mu(v, c, \alpha)<t \leq v-c$ and $\lambda(v, c$, $t)<t \leq(v-c) / 2$, an oligopoly equilibrium exists only in mixed strategies. Behavior in the regions of mixed strategy equilibria, which is not formally considered here, may be characterized by sporadic advertising campaigns or by randomized pricing strategies. ${ }^{9}$

To develop some further insight on these different outcomes, consider the advertising cost specialization of Butters (1977), $A(\phi ; \alpha)=$ $-\alpha \ln (1-\phi)$. Let $c=0$ so that $v$ denotes the net social value of consumption (gross of transportation costs). The outcome of the model for various $(t, v)$ pairs is depicted in Fig. 1 . The 45 -degree line $\hat{v}=t$ depicts the boundary between the incomplete coverage region and the local monopoly region. For $(t, v)$ pairs to the right of this line, a

\footnotetext{
${ }^{9}$ Under complete coverage there is an incentive for firms to defect from a pure price strategy to the reservation price for partially informed consumers, $p=v-t$, whereas under incomplete coverage there is an incentive for firms to defect from a pure price strategy to the local monopoly price, $p=t+c$.
}

local monopoly equilibrium emerges. The locus at $v^{u}=2 t$ denotes the upper boundary of the incomplete coverage region. The incomplete coverage region is comprised of all $(t, v)$ pairs between this locus and the 45-degree line. This region is further divided by the locus $v^{l}=3 t / 2-2 \alpha$, with the area above the $v^{l}$ locus representing $(t, v)$ pairs that support a Nash equilibrium in pure strategies, and the area between the $v^{l}$ locus and the 45-degree line representing the region where an equilibrium exists only in mixed strategies. The locus $\tilde{v}$ similarly divides the complete coverage region into regions with pure strategy and mixed strategy equilibria.

Numerical results for this advertising specialization are presented in Section 4.4. The numerical analysis calculates the outcomes for prices and advertising for variations in $t$, which amounts to fixing a value of $v$ on the vertical axis of Fig. 1 and moving laterally through the different market regions as the degree of product differentiation increases.

\section{Social optimum}

This section compares the equilibrium outcomes of the model with the socially optimal resource allocation. An obstacle in the way of making such a comparison is that the socially optimal advertising intensity depends on the market coverage at the efficient prices $\left(p^{*}=c\right)$, and this differs from the equilibrium prices. For this reason, the social level of market coverage and the private level of market coverage generally do not coincide. In GS, this problem is handled by calibrating the output levels prior to optimization with the "largegroup" assumption of Dixit and Stiglitz (1977). In Stegeman (1991) and Stahl (1994), this issue is sidestepped by inferring welfare implications indirectly from the advertising level selected by the highest-priced firm. Here, following Spence (1975), a "partial view" of advertising is taken that involves comparing the equilibrium advertising outcome to the socially optimal advertising allocation conditional on the equilibrium market prices. Specifically, the social price level is fixed at $p^{*}=p^{e}$ for all advertising comparisons, where $p^{e}$ is the equilibrium price level, and the social and private return to advertising is compared at this (common) price level in each region.

\subsection{Local monopoly}

The socially optimal advertising allocation depends on industry profits and the surplus consumers receive from purchasing a brand (net of transportation costs) in the market. Under local monopoly, a consumer receives an advertising message from the representative brand with probability $\hat{\phi}$. At a price of $\hat{p}^{*}=\hat{p}^{e}$, some consumers purchase the brand and some do not. The conditional probability that a consumer buys the product after receiving the advertising message is $\left(v-\hat{p}^{e}\right) / t$. Conditional on this sale, producer surplus for the advertising firm is $\hat{p}^{e}-c$ and consumer surplus per brand (on average) is $v-\hat{p}^{e}-T$, where $T$ is travel cost. Because the average consumer who purchases the brand travels a distance of $\left(v-p^{e}\right) / 2 t$, travel cost for this consumer is $T=\left(v-\hat{p}^{e}\right) / 2$, so that consumer surplus per brand (on average) is $\left(v-\hat{p}^{e}\right) / 2$.

Aggregate welfare, which is taken to be the sum of consumer surplus and producer surplus in both local monopoly regions, is given by

$\hat{W}=\frac{2 \hat{\phi}\left(v-\hat{p}^{e}\right)}{t}\left(\frac{v-\hat{p}^{e}}{2}+\hat{p}^{e}-c\right)-2 A(\hat{\phi} ; \alpha)$.

The change in social welfare resulting from a (bilateral) change in advertising frequency is

$\frac{\partial \hat{W}}{\partial(2 \hat{\phi})}=\frac{\left(v-\hat{p}^{e}\right)^{2}}{2 t}+\frac{\left(v-\hat{p}^{e}\right)\left(\hat{p}^{e}-c\right)}{t}-A_{\phi}(\hat{\phi} ; \alpha)$. 
A small increase in $\hat{\phi}$ that informs one more consumer induces a purchase with frequency $\left(v-\hat{p}^{e}\right) / t$, and the additional sale contributes $\left(v-\hat{p}^{e}\right) / 2$ (on average) to consumer surplus and $\hat{p}^{e}-c$ to producer surplus. The marginal social return to advertising in Eq. (16) is the sum of these surplus gains less the marginal social cost of advertising.

The efficiency of the market advertising outcome can be assessed by evaluating the welfare change in Eq. (16) at the market advertising level, $\hat{\phi}=\hat{\phi}^{e}$. Upon substitution from Eq. (7),

$\left.\frac{\partial \hat{W}}{\partial(2 \hat{\phi})}\right|_{\hat{\phi}=\hat{\phi}^{e}}=\frac{\left(v-\hat{p}^{e}\right)^{2}}{2 t}>0$.

Proposition 1. (Shapiro, 1980). Informative advertising is undersupplied under local monopoly.

The reason a local monopolist undersupplies purely informative advertising is that only the market size effect is at work in the industry. There are no matching or business-stealing effects under monopoly because the demand regions of firms do not overlap. The only distortion that remains in the market advertising level arises from the monopolists' inability to appropriate the gain in consumer surplus resulting from reduced cost of consumer search. Specifically, the social benefit of an additional purchase, $v-c-t x$, exceeds the private benefit, $p-c$, by the amount of surplus consumers receive in the market, $v-p-t x$. As a result, the magnitude of the advertising inefficiency is the product of the additional customers anticipated from a marginal advertising unit, $(v-\hat{p}) / t$, and the average level of consumer surplus a sale provides, $(v-\hat{p}) / 2$.

\subsection{Incomplete coverage}

Under incomplete coverage, a consumer receives advertising messages from both brands with probability $\phi^{2}$ and becomes fully informed. Each fully informed consumer purchases the nearest brand, and this generates net surplus (on average) of $v-p^{e}-t / 4$. With probability $2 \phi(1-\phi)$, a consumer receives an advertising message from only one of the two brands. Among these partially informed consumers, some choose to purchase the advertised brand and others do not. The conditional probability that a consumer makes a purchase given that a single advertising message is received is $\left(v-p^{e}\right) / t$. Thus, the probability that a consumer receives a single ad and also finds it worthwhile to consume the brand is $2 \phi(1-\phi)\left(v-p^{e}\right) / t$. Partiallyinformed consumers who make a purchase travel a distance of $\left(v-p^{e}\right) / 2 t$ (on average), and this generates net consumer surplus of $\left(v-p^{e}\right) / 2$.

Aggregate welfare is given by the sum of consumer surplus and producer surplus,

$$
\begin{aligned}
W= & \phi^{2}\left(v-p^{e}-\frac{t}{4}\right)+\frac{\phi(1-\phi)\left(v-p^{e}\right)^{2}}{t} \\
& +\frac{\phi\left(p^{e}-c\right)}{t}\left[2(1-\phi)\left(v-p^{e}\right)+\phi t\right]-2 A(\phi ; \alpha) .
\end{aligned}
$$

The third and fourth terms on the right-hand side of the welfare expression are industry profits.

The change in social welfare resulting from a bilateral change in advertising frequency is

$$
\begin{aligned}
\frac{\partial W}{\partial(2 \phi)}= & (1-\phi) \frac{\left(v-p^{e}\right)^{2}}{2 t}+\phi\left(v-p^{e}-\frac{t}{4}-\frac{\left(v-p^{e}\right)^{2}}{2 t}\right) \\
& +\frac{p^{e}-c}{t}\left((1-2 \phi)\left(v-p^{e}\right)+\phi t\right)-A_{\phi}
\end{aligned}
$$

Proceeding as above by evaluating the welfare change at the market advertising level, $\phi=\phi^{e}$ in Eq. (10), the welfare change can be expressed, after slight manipulation, as

$$
\begin{aligned}
\left.\frac{\partial W}{\partial(2 \phi)}\right|_{\phi=\phi^{e}}= & \left(1-\phi^{e}\right) \frac{\left(v-p^{e}\right)^{2}}{2 t}+\phi^{e}\left(v-p^{e}-\frac{t}{4}-\frac{\left(v-p^{e}\right)^{2}}{2 t}\right) \\
& -\phi^{e}\left(\frac{p^{e}-c}{t}\right)\left(v-p^{e}-\frac{t}{2}\right) .
\end{aligned}
$$

Condition (17) has an intuitive interpretation. A marginal increase in $\phi$ informs a previously uninformed customer with probability $(1-\phi)$. With probability $\left(v-p^{e}\right) / t$, this customer also purchases the product, generating social surplus (on average) of $\left(v-p^{e}\right) / 2$. The expected social value of informing a previously uninformed consumer is the market size effect: $\left(1-\phi^{e}\right) \frac{\left(v-p^{e}\right)^{2}}{2 t}>0$. The market size effect causes advertising to be undersupplied. With probability $\phi$, the marginal consumer becomes fully informed. The resulting consumption generates social surplus (on average) of $v-p^{e}-t / 4$, but entails the opportunity $\operatorname{cost}\left(v-p-p^{e}\right)^{2} / 2 t$. The expected social value of fully informing a consumer is the matching effect, $\phi^{e}\left(v-p^{e}-\frac{t}{4}-\frac{\left(v-p^{e}\right)^{2}}{2 t}\right)$. The matching effect causes advertising to be undersupplied. ${ }^{10}$ When the marginal consumer becomes fully informed, however, this also intensifies the oligopoly rivalry between firms. Advertising by one firm imposes a negative externality on the rival firm's sales, and the value of the loss in sales is represented by the difference between the marginal contribution of advertising to aggregate profits and the marginal contribution of advertising to individual profit. This is the business-stealing effect, $\frac{-\phi^{e}\left(p^{e}-c\right)}{t}\left(v-p^{e}-\frac{t}{2}\right)<0$. The business-stealing effect causes advertising to be oversupplied.

Proposition 2. Under incomplete coverage, informative advertising is undersupplied for values of $t$ close to $\mu(v, c, \alpha)$; informative advertising is undersupplied for values of $t$ close to $(v-c) / 2$ when advertising costs are sufficiently high and otherwise oversupplied.

\section{Proof. See Appendix A.}

The relationship between the market advertising level and the socially optimal advertising level depends jointly on the degree of product differentiation $(t)$ and on advertising costs $(\alpha)$ in the market. The reason is that the market size effect exists only for partially informed consumers, who become aware of a brand with frequency $1-\phi^{e}$, while the matching effect and business-stealing effect exists only for fully informed consumers, who become aware of both brands with frequency $\phi^{e}$. As advertising costs decrease, $\phi^{e}$ rises, increasing the population of fully-informed consumers on the interval, which weakens the market size effect and strengthens the matching effect and business-stealing effect in the market.

\subsection{Complete coverage}

Under complete coverage, all consumers who receive at least one advertising message purchase the good. The gross value of consumption is $v-\tilde{p}^{e}$ for each consumer, regardless of the consumer's location in the product space. Total transportation costs, however, depend on the extent to which consumers at each location are aware of the existence of individual brands.

With probability $\tilde{\phi}^{2}$, a consumer receives both advertising messages. This consumer travels (on average) $1 / 4$ the length of the unit segment to make a purchase, which generates the social net benefit of $v-\tilde{p}^{e}-t / 4$. With probability $2 \tilde{\phi}(1-\tilde{\phi})$, a consumer receives exactly one advertising message. This message is equally likely to be received from the nearest brand as from the farthest brand, so that a

\footnotetext{
${ }^{10}$ Formally, $v-p^{e}-t / 4-\left(v-p^{e}\right)^{2} / 2 t=v-p^{e}-t / 2-\left(v-p^{e}\right)\left(v-p^{e}-t\right) / t>0$, which is positive by the definition of incomplete coverage $\left(v-p^{e}<t\right)$.
} 


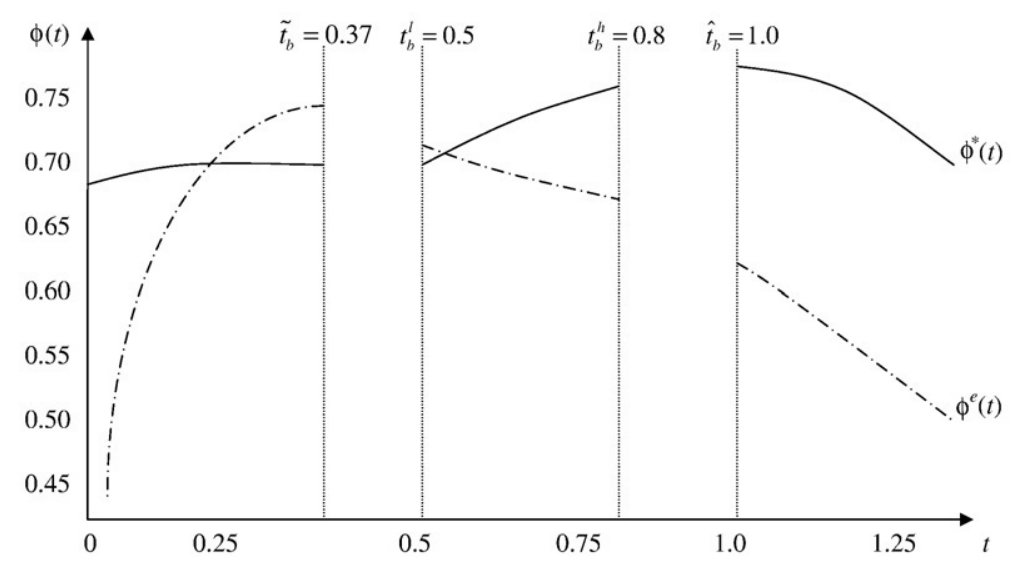

Fig. 2. Advertising outcomes when advertising costs are "low" ( $v=1, c=0, \alpha=0.1)$.

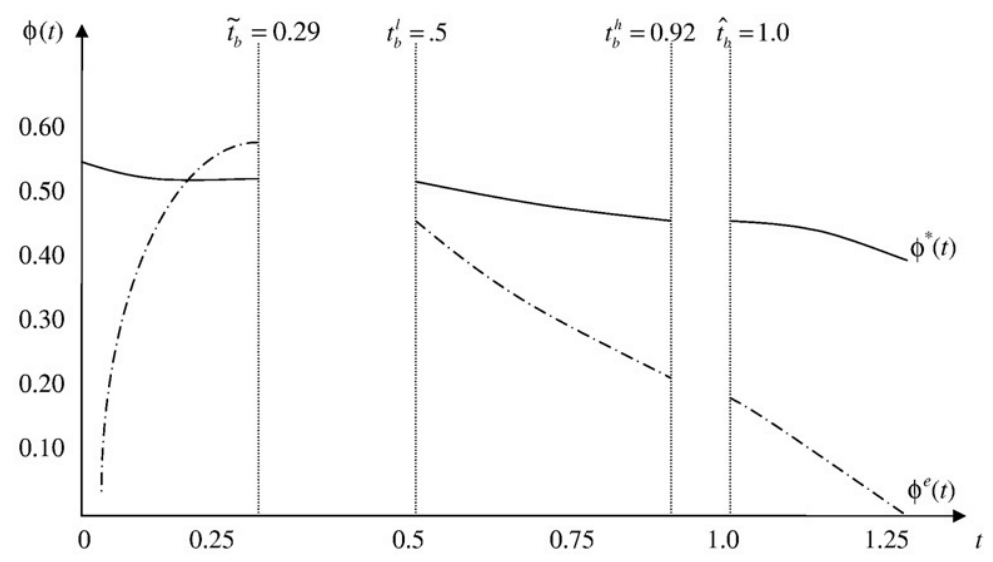

Fig. 3. Advertising outcomes when advertising costs are "high" $(v=1, c=0, \alpha=0.2)$.

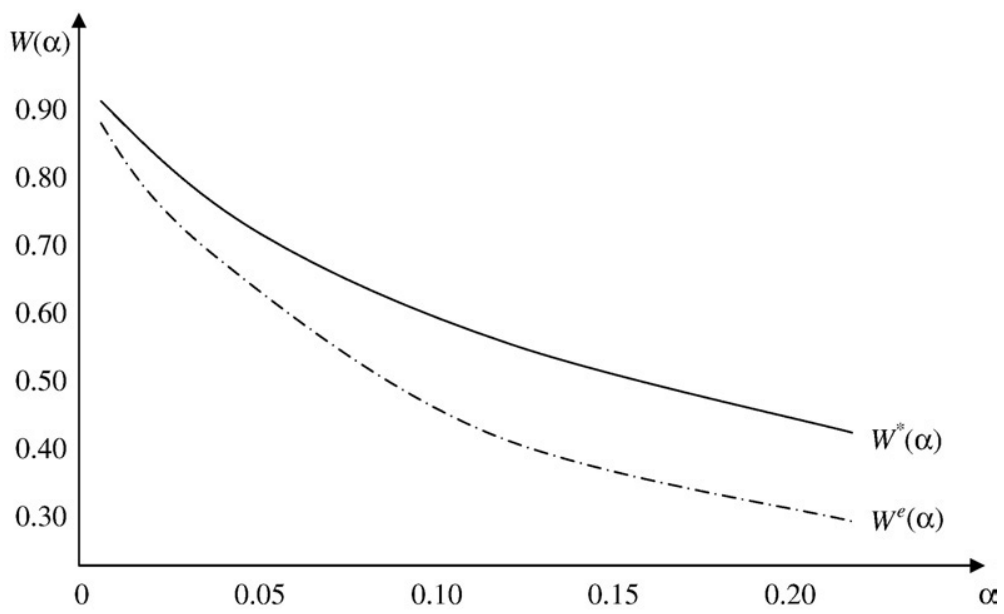

Fig. 4. Welfare outcomes under complete coverage with variations in advertising costs $(v=1, c=0, t=0.1)$.

the market equilibrium position $\left(p^{e}, \phi^{e}\right)$ and at the socially optimal resource allocation $\left(p^{*}=0, \phi^{*}\right)$ for both levels of oligopoly market coverage. This provides a full welfare assessment of the market outcome under both pricing and advertising distortions. In each case, the net value of consumption is given by $v=1$ and $c=0$ and the degree of product differentiation is selected to maintain the equilibrium level of market coverage for the range of advertising costs considered. ${ }^{13}$

\footnotetext{
${ }^{13}$ For the entire range of incomplete coverage, the social price level $\left(p^{*}=0\right)$ results in complete coverage.
}

Fig. 4 displays the private and social welfare outcomes in response to changes in advertising cost $(\alpha)$ under complete coverage. The degree of product differentiation is fixed in each case at $t=0.1$, and the private and social welfare outcomes are numerically calculated for variations in $\alpha$. (Under complete coverage, the difference in welfare is due only to variations in social and private advertising levels, because prices serve only to redistribute rents.) Notice that the welfare level in the market equilibrium approaches the social optimum as advertising costs decline (i.e., moving right to left as $\alpha$ decreases). Innovations that reduce advertising costs result in a convergence of welfare outcomes under complete coverage. 


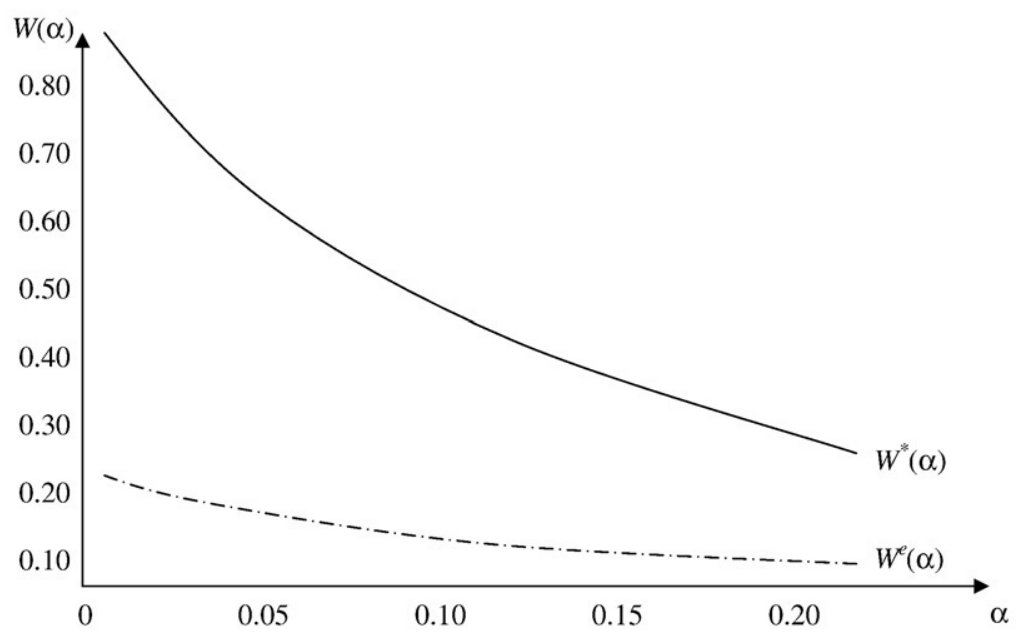

Fig. 5. Welfare outcomes under incomplete coverage with variations in advertising costs $(v=1, c=0, t=0.6)$.

Fig. 5 compares the private and social welfare outcomes in response to changes in advertising cost $(\alpha)$ under incomplete coverage (for $t=0.6$ ). Notice that advertising cost innovations that reduce $\alpha$ cause the market equilibrium outcome to diverge from the socially optimal resource allocation under incomplete coverage. The reason is that a rise in prices (advertising fixed) leads to a decrease in the level of market sales. As advertising costs decrease, the welfare level rises sharply in the socially optimal resource allocation, but remains relatively flat in the market allocation, as greater advertising frequencies decrease the demand elasticities facing firms and increase the equilibrium market prices. Higher market prices deter sales, and this dampens the return to innovations that reduce advertising costs.

\section{Concluding remarks}

This paper has considered a model of purely informative advertising with differentiated products. Advertising informs consumers about prices and the attributes of products, and doing so improves the matches between consumers and brands. Relative to the social optimum, advertising levels in the market equilibrium were shown to be too low when the competing brands are highly substitutable, too high when the brands are moderately differentiated, and too low again when the brands are highly differentiated.

Advertising cost innovations that improve the delivery of ads (expenditure given) have disparate affects on welfare that depend on the degree of product differentiation in the market. At low levels of product differentiation, a decrease in advertising costs causes equilibrium prices and advertising levels to converge towards the socially optimal levels, whereas divergence occurs at higher levels of product differentiation.

A number of empirical studies have found advertising to create both market size effects and to alter the market shares of firms. For example, Roberts and Samuelson (1988) find cigarette advertising increased total market demand without a significant influence on market shares, while Nelson (1999) finds advertisements for beer, wine and distilled spirits altered market shares among advertised brands without an appreciable affect on market demand. The present model highlights the importance of isolating these effects in empirical studies of advertising. In industrial settings where advertising produces negligible effects on market size, advertising is more likely to be oversupplied and technological innovations that reduce advertising costs can lead to a deterioration of market performance.

\section{Appendix A}

Proof of Proposition 2. First consider the case in which $t=\mu(v, c, \alpha)$. In this case, a symmetric, pure strategy equilibrium emerges in which $v-p^{e}=t / 2$. Making this substitution into Eq. (17) and expressing the boundary in terms of $\phi^{e}$ yields

$$
\left.\frac{\partial W}{\partial(2 \phi)}\right|_{t=\mu(v, c, \alpha)}=\frac{2(v-c)}{\left(4-\phi^{e}\right)}\left[\frac{\left(2-\phi^{e}\right)}{8}-\frac{\phi^{e}\left(1-\phi^{e}\right)}{\left(2-\phi^{e}\right)\left(4-3 \phi^{e}\right)}\right] .
$$

The sign of this expression is given by the sign of the term $k=$ $\left(2-\phi^{e}\right)^{2}\left(4-3 \phi^{e}\right)-8 \phi^{e}\left(1-\phi^{e}\right)$. Factoring terms yields $k=4\left(1-\phi^{e}\right)^{2}$ $\left(4-\phi^{e}\right)+\phi^{e^{3}}>0$. Next consider the case in which $(v-c) / t=2$. In this case, a symmetric, pure strategy equilibrium emerges in which $v-p^{e}=t$. Making this substitution into Eq. (17) yields

$$
\left.\frac{\partial W}{\partial(2 \phi)}\right|_{t=(v-c) / 2}=\frac{(v-c)}{8}\left(2-3 \phi^{e}\right)
$$

The equilibrium advertising levels rise monotonically in the range $\phi^{e} \in(0,1)$ with innovations in advertising technology (i.e., smaller $\alpha$ ); hence a critical value of $\alpha$ exists, denoted $\alpha^{c}$, for which $\phi^{e}\left(\alpha^{c}\right)=2 / 3$. The remainder of the proof holds by continuity.

Proof of Proposition 3. Making use of Eq. (13), expression Eq. (19) can be written as

$\left.\frac{\partial W}{\partial(2 \tilde{\phi})}\right|_{\tilde{\phi}=\tilde{\phi}^{e}}=\frac{1}{4}\left[4\left(1-\tilde{\phi}^{e}\right)(v-p)-\left(6-5 \tilde{\phi}^{e}\right) t\right]$

At the lower boundary of the complete coverage region, $t=\lambda(v, c, \alpha)$, a symmetric, pure strategy equilibrium emerges in which $v-p^{e}=t$. Making this substitution in (A.1) yields

$\left.\frac{\partial W}{\partial(2 \tilde{\phi})}\right|_{t=\lambda(v, c, \alpha)}=\frac{-\tilde{\phi}^{e}\left(2-\tilde{\phi}^{e}\right)(v-c)}{8}<0$.

The market equilibrium involves an inefficiently high level of advertising under complete coverage in the neighborhood of $t=\lambda(v$, $c, \alpha)$ (by continuity). For smaller values of $t$, note by the implicit function theorem on Eqs. (13) and (14), that $d \tilde{p}^{e} / d t<0$ and $d \tilde{\phi}^{e} / d t>0$. 
In the limit as $t \rightarrow 0$, the price and advertising levels converge to $\tilde{p}^{e} \rightarrow c$ and $\tilde{\phi}^{e} \rightarrow 0$. It follows that the right-hand side of (A.1) converges to $4(v-c)>0$ and advertising is undersupplied.

\section{References}

Butters, Gerard, 1977. Equilibrium distributions of sales and advertising prices. Review of Economic Studies 44 (3), 465-491.

Dixit, Avinash K., Stiglitz, Joseph E., 1977. Monopolistic competition and optimum product diversity. American Economic Review 67 (3), 297-308.

Gary-Bobo, Robert J., Michel, Philippe, 1991. Informative advertising and competition: A non-cooperative approach. International Economic Review 32 (3), 321-339.

Grossman, Gene, Shapiro, Carl, 1984. Informative advertising with differentiated products. Review of Economic Studies 51 (1), 63-81.

Hotelling, Harold, 1929. Stability in competition. The Economic Journal 37 (1), 41-57.

Iyer, Ganesh, Soberman, David A., Villas-Boas, J. Miguel, 2005. The targeting of advertising. Marketing Science 24 (3), 461-476.

Lancaster, Kevin, 1975. Socially optimal product differentiation. American Economic Review 65 (4), 567-585.
Nelson, Jon P.. 1999. Broadcast advertising and U.S. demand for alcoholic beverages. Southern Economic Journal 65 (2), 774-790.

Roberts, Mark, Samuelson, Larry, 1988. An empirical analysis of dynamic nonprice competition in an oligopolistic industry. Rand Journal of economics 19 (1), 200-220.

Schmalensee, Richard, 1986. Advertising and market structure. In: Stiglitz, J.E., Mathewson, G.F. (Eds.), New developments in the analysis of market structure. MIT Press, Cambridge, MA, pp. 373-396.

Salop, Steven, 1979. Monopolistic competition with outside goods. Bell Journal of Economics 10, 141-156 February.

Shapiro, Carl, 1980. Advertising and welfare: comment. Rand Journal of Economics 12 (2), 749-751.

Soberman, David A., 2004. Research note: additional learning and implications on the role of informative advertising. Management Science 50, 1744-1750.

Spence, Michael, 1975. Monopoly, quality and regulation. Bell Journal of Economics 6, $417-429$.

Stahl, Dale O., 1994. Oligopolistic pricing and advertising. The Journal of Economic Theory $64,162-177$.

Stegeman, Mark, 1991. Advertising in competitive markets. American Economic Review 81 (1), 210-223. 